\title{
On the Predictability of Japanese Stock Returns using Dividend Yield
}

\author{
Kohei Aono \\ and \\ Tokuo Iwaisako
}

August 18, 2009

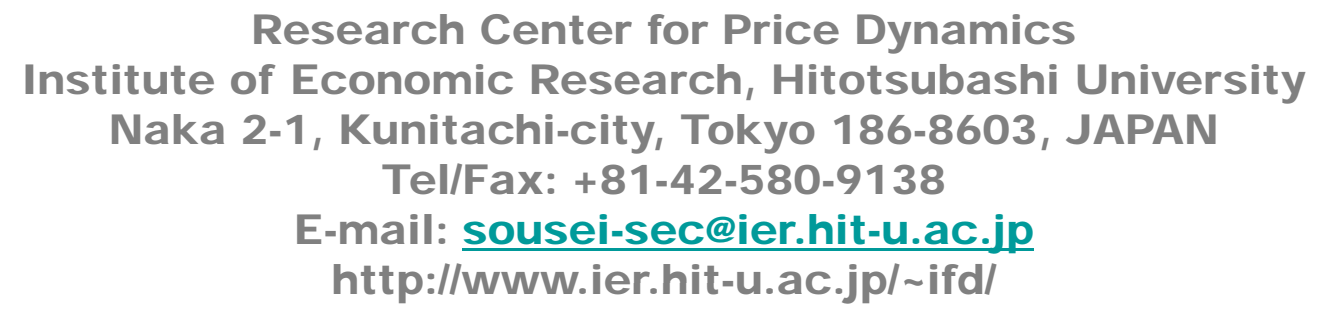




\title{
On the Predictability of Japanese Stock Returns using Dividend Yield
}

\author{
Kohei Aono $\dagger$ \\ College of Business Administration, Ritsumeikan University \\ and \\ Tokuo Iwaisako \\ Policy Research Institute, Ministry of Finance, Government of Japan and \\ Institute of Economic Research, Hitotsubashi University.
}

\begin{abstract}
$\underline{\text { Abstract }}$
The aim of this paper is to provide a critical and comprehensive reexamination of empirical evidence on the ability of the dividend yield to predict Japanese stock returns. Our empirical results suggest that in general, the predictability is weak. However, (1) if the bubble economy period (1986-1998), during which dividend yields were persistently lower than the historical average, is excluded from the sample, and (2) if positive autocorrelation in monthly aggregate returns is taken into account, there is some evidence that the log dividend yield is indeed useful in forecasting future stock returns. More specifically, the log dividend yield contributes to predicting monthly stock returns in the sample after 1990 and when lagged stock returns are included simultaneously.
\end{abstract}

Keywords: dividend yield; stock returns; structural break test.

JEL classification: C32, G17.

$\dagger$ Corresponding author.

Address: 1-1-1 Noji-Higashi, Kusatsu, Shiga 525-8577, JAPAN

E-mail address: <kaono@tkh.att.ne.jp>

Acknowledgement

The authors are particularly grateful to Tomoyoshi Yabu for his help in obtaining the computer program for the structural break test, as well as his suggestions for our paper. We also thank Tatsuyoshi Okimoto, Toshiaki Watanabe, and the seminar participants at Hitotsubashi University and the Japanese Economic Association meeting in Fall 2007 for their comments. The views expressed in this paper are the author's own and not necessarily those of the Ministry of Finance. Iwaisako gratefully acknowledges financial assistance from the Japan Society for the Promotion of Science (\#18330067). 


\section{Introduction}

The conventional present value relationship suggests that the "dividend yield" or "price-dividend ratio" is useful in explaining the behaviors of stock prices (see Campbell, Lo, \& MacKinlay 1997, Chap. 7 for a review). Accordingly, there is a large literature examining the ability of the dividend yield to predict future stock returns. Empirical studies of US data include Fama \& French (1988), Mankiw \& Shapiro (1986), Stambaugh (1986, 1999), Lewellen (2004), Torous, Valkanov \& Yan (2004), Campbell \& Yogo (2006), Ang \& Bekaert (2007), and Cochrane (2008) among others.

One of the main focuses of recent literature on this topic is reexamination of the statistical inference incorporating the fact that dividend yields are highly persistent processes. In the first half of this short paper, following the statistical procedure proposed by Campbell \& Yogo (2006), we provide a comprehensive reexamination of stock return predictability using the dividend yield for Japanese data. Specifically, our paper follows the recent works by Lewellen (2004) and Campbell \& Yogo (2006), who reexamine the predictive ability of the dividend yield by extending the "predictive regression" framework developed by Stambaugh $(1986,1999)$. Predictive regression implicitly assumes a version of the no-bubble condition. However, we suspect that such a no-bubble condition might have been violated in the latter half of the 1980s, during the so-called "bubble economy" period. In Section 2, we first estimate a univariate model of the dividend yield and find structural breaks around the bubble economy period. Hence, we apply the predictive regression framework for both the full sample and the subsample starting from the early 1990s and find that the predictive ability of the dividend yield seems to improve in the subsample result.

In the second half of the paper, we consider whether the dividend yield forecasts stock returns in the presence of other explanatory variables such as lagged returns. We find that the dividend yield tends to have higher explanatory power when lagged returns are included in the regression in Section 3. Section 4 concludes the paper.

\section{The Predictability in the "Predictive Regres- sion" Framework}

\subsection{The predictive regression framework}

In this section, we reexamine the ability of dividend yields to forecast future stock returns by adopting the "predictive regression" framework employed 
by Stambaugh $(1986,1999)$, Lewellen (2004), and Campbell \& Yogo (2006). The literature starts with Stambaugh (1986), who considers the forecastability of stock returns in the following simple framework:

$$
\begin{aligned}
& r_{t}=\alpha+\beta x_{t-1}+u_{t} \\
& x_{t}=\gamma+\rho x_{t-1}+\epsilon_{t}
\end{aligned}
$$

where $r_{t}$ is stock return and $x_{t}$ is log dividend yield. Forecasting regressions typically include other forecasting variables such as the short-term interest rate and possibly its lagged values. However, the simple formulation above allows researchers to analyze the relationship more carefully and rigorously.

In an asset pricing model with the no-bubble condition imposed, the stock price is equal to the present values of future cashflows discounted by time-varying discount rates. Hence the conventional wisdom in finance suggests that the ratio of asset price to current cash flow, such as the dividend yield or PER, predicts future stock returns. However, statistical inference of such a predictive regression in practice is difficult for several reasons. First, because the stock price is much more volatile than the dividend process, the movement in $\log$ dividend yield $x_{t}$ tends to be dominated by stock price movement. Second, because the stock price is very persistent and has a dominant effect on the dividend yield, $x_{t}$ also exhibits strong persistence. Theoretically, the dividend yield $x_{t}$ should be a stationary variable even if the stock price and dividend are both $I(1)$ variables. However, in practice, it is often difficult to reject the null that $x_{t}$ is a unit root process, i.e., $x_{t}$ is a near unit root process. Finally, because the stock price affects both the stock return and the dividend yields, their error terms $u_{t}$ and $\epsilon_{t}$ will be negatively correlated. These issues are addressed in the previous studies mentioned at the beginning of this subsection.

\subsection{Are Japanese dividend yields stationary?}

A difficulty we face with the Japanese stock market data is the treatment of the asset price bubble in the late 1980s. The Tokyo market experienced dazzling asset price escalation for several years in the late 1980s followed by a sharp downturn at the beginning of 1990s. This large swing in stock prices resulted in a sharp decline and the subsequent rebound of dividend yields in this period as shown in Figure 1.

[Insert Figure 1 about here] 
If a long historical data set is available, it can be considered a series of temporary deviations of stock prices from their fundamental values. However, given the limited length of reliable Japanese stock market data compared with the US and UK, a historical one-time event of this magnitude causes serious problems for statistical inference in the predictive regression framework, because the asset price bubble in the late 1980s makes the dividend yield series even more persistent. Theoretically, this suggests that we should consider the asset price bubble in the late 1980s to be different qualitatively from average episodes of excess volatility, therefore we assume that the no-bubble condition was violated in this period.

For this reason, in this paper, we deal with the "bubble economy" in the following manner. First, we estimate a univariate AR model for the $\log$ dividend yield and test for a possible structural break(s) to detect the period in which the no-bubble condition had been violated. In the second step, we examine the predictive ability of the dividend yield in equation (1) by applying the statistical procedure proposed by Campbell \& Yogo (2006) to the subsample identified in the first step.

Table 1 presents the results of the structural break tests for the $\operatorname{AR}(1)$ model for the dividend yields. We report two types of critical values here. The first one is the critical values in Bai \& Perron's $(1998,2003)$ methodology, which allows multiple structural breaks at unknown points. We assume that there are no more than five structural breaks in the full sample. However, Bai \& Perron's procedure has a potential problem because it assumes that each subsample is stationary. Empirically, the dividend yields are highly persistent processes, so we cannot reject the null of a unit root even if we are convinced that it is a stationary process based on economic theory.

When Bai \& Perron's test procedure is applied to the full sample from 1970 to 2006, we find four or five statistically significant structural breaks. It is very difficult to justify this result because some of the subsamples are extremely short. Furthermore, it is unnatural that the dividend yield series has structural breaks every six to seven years. Therefore, in Table 1 we report the results for when Bai \& Perron's test is applied to the subsample starting in 1980, excluding early observations corresponding to the first oil crisis. The empirical results suggest that there are up to two structural breaks in this sample period. If only one break is allowed, the break point is at the end of 1989. If two breaks are allowed, these occur in the second half of 1985 and December 1989/January 1990.

[Insert Table 1 about here] 
Since Bai \& Perron's test procedure yeild such unstable results, we also employ the structural break test developed by Pierre Perron and his coauthors (Perron \& Yabu 2009, Kejriwal \& Perron 2008), which explicitly allows the possibility of nonstationarity in the subsample data. Applying the Kejriwal-Perron-Yabu break test to Japanese log dividend yields data produces somewhat different results from those using the Bai-Perron test discussed above. Both procedures find two break points before and after the stock market bubble in late 1980s, but the exact dates are different. Break points found by the Kejriwal-Perron-Yabu test are January 1987 and August 1990. Furthermore, the Kejriwal-Perron-Yabu procedure finds more significant breaks before the bubble in 1987 than after the collapse of the bubble in 1990 .

Although investigating why these two break tests yield different break points is an interesting econometric question, answering it is beyond the scope of this paper. What is important in the current context is that, despite the differences in details, both the Bai-Perron and Kejriwal-Perron-Yabu tests find that log dividend yield has a break point after the collapse of the bubble in 1990. Hence, in the following empirical analysis, we mainly focus on the subsample starting from 1990.

\subsection{Empirical results}

Let us consider the statistical inference of $\widehat{\beta}$ in (1). In testing the significance of $x_{t-1}$ in predicting $r_{t}$, we have to take care of the near unit root problem of the dividend yield process $x_{t}$ and the correlation of error terms $\epsilon_{t}$ and $u_{t}$. Lewellen (2004) and Campbell \& Yogo (2006) handled this problem by constructing a confidence interval for $\beta$, conditioned by the values of $\rho$. In particular, we closely follow the procedure of Campbell \& Yogo (2006) in this paper who state that:

A regression of stock returns onto a lagged financial variable has low power because stock returns are extremely noisy. If we can eliminate some of this noise, we can increase the power of the test. When the innovations to returns and the predictor variable are correlated, we can subtract off the part of the innovation to the predictor variable that is correlated with returns to obtain a less noisy dependent variable for our regression. (Campbell \& Yogo 2006, p.29).

The results of the DF-GLS test and the $Q$ test with the Bonferroni correction are presented in Table 2 and Figure 2. The test applied to the full 
sample clearly rejects stock return predictability both at the monthly and quarterly frequency. The full sample monthly result even suggests the point estimate of $\widehat{\beta}$ is negative. On the other hand, the sub sample period estimation using post-1990 data shows some improvements in predictability. The estimated $\widehat{\beta}$ coefficients are much higher with the subsample results. The Bonferroni confidence intervals shown in Figure 2 suggest obvious improvements in predictive ability of the dividend yields in the 1990s subsample compared with the full sample, especially with quarterly data. However, the overall evidence is too weak to conclude that the dividend yield is a useful predictor even in the subsample estimate.

[Insert Table 2 and Figure 2 about here]

\section{The Predictive Ability of Financial Ratios with Lagged Returns}

It is rather disappointing that we cannot confirm the predictive ability of the dividend yield even with the recently improved statistical methods. However, this is unsurprising because, in our previous studies (Aono \& Iwaisako 2008,2009 ), we find that the most powerful predictor of aggregate Japanese stock returns is own lagged returns. While there are many potential forecasting variables, this leads us to the examination of the forecasting ability of dividend yields along with lagged returns.

Table 3 reports estimation results for regression (1) including log dividend yields and lagged returns as forecasting variables.

[Insert Table 3 about here]

In both the full sample and subsample results, lagged returns are positively correlated with current returns. This is consistent with the findings in our previous studies. In the full sample regression, the coefficient of the dividend yield is insignificant. In the subsample starting from 1990, the coefficient of the dividend yield is much higher than the full sample and statistically significant at the $5 \%$ level. Overall, our empirical result suggests that dividend yields are useful in predicting future stock returns only in the subsample after the bursting of the bubble. 


\section{Concluding Remarks}

In this paper, we reexamined the predictive ability of the dividend yield using aggregate Japanese stock return data. Our empirical results suggested two important points. First, there is a structural break in the (log) dividend yield series at the end of 1989, induced by the asset price bubbles in the Tokyo market in the late 1980s. Hence, the evaluation of a predictive regression with Japanese data requires consideration of this point. Second, even with the subsample data after the bursting of the bubble in early 1990 , the predictive power of the dividend yield is found to be significant only when it is included with lagged returns. In other words, the autocorrelation in aggregate stock returns has to be taken into account in evaluating the usefulness of forecasting variables using Japanese data.

Some important issues are left unexplored in this paper. First, there is ongoing debate about the stationarity/nonstationarity of dividend yields and the dividend payout process itself (Ang \& Bekaert 2007; Cochrane 2008). In this paper, we implicitly assumed the conventional position that the stock price and dividend payout processes are nonstationarity, while dividend yields are stationary. Close examination of the stationarity of the dividend payout process with Japanese data is, however, still an important subject of the research. Second, we assumed the existence of autocorrelation in aggregate stock returns as a given statistical fact in our analysis in Section 3. However, the source of such autocorrelation is an important issue. Preliminary empirical results suggest that the lead-and-lag relationship runs from large stocks to small stocks in the sense of Lo \& MacKinlay (1990a, b), and provides a reasonable explanation (Aono \& Iwaisako 2009). Finally, we only considered the short-horizon predictability in this paper. Reexamination of the long-run forecasting regression and predictors other than dividend yields and lagged returns is the subject of our future research.

The predictability of aggregate stock returns is an old problem in finance. Yet there are many aspects of this topic that have not been fully explored using Japanese data. Examining the dividend yield as a forecasting variable, this paper found that when the autocorrelation of stock returns is taken into account and the sample is limited to after 1990 to avoid the asset bubbles in late 1980s, stock return predictability does exist. Still, there are many more things to be reexamined about the predictability of Japanese stock returns. 


\section{$\underline{\text { References }}$}

- Ang, A. \& Bekaert G. (2007) Stock Return Predictability: Is It There? Review of Financial Studies 20 651-707.

- Aono K., \& Iwaisako, T. (2008) The Consumption-Wealth Ratio, Real Estate Wealth, and the Japanese Stock Market. Institute of Economic Research Discussion Paper, \#A.504, Hitotsubashi University.

- Aono K., \& Iwaisako, T. (2009) Aggregate Return Predictability and the Cross-section of Japanese Stock Returns. the paper presented at NFA association annual meeting, May 2009.

- Bai J. \& Perron P. (1998) Estimating and Testing Linear Models with Multiple Structual Changes. Econometrica 66, 47-78.

- Bai J. \& Perron P. (2003) Computation and Analysis of Multiple Structual Change Models. Journal of Applied Econometrics 18, 1-22.

- Campbell, J.Y., Lo, A.W., \& MacKinlay, A.C. (1997) The Econometrics of Financial Markets. Princeton University Press, Princeton, NJ.

- Campbell, J.Y. \& Yogo, M. (2006) Efficient tests of stock return predictability. Journal of Financial Economics 81, 27-60.

- Cochrane, J.H. (2008) The Dog That Did Not Bark: A Defense of Return Predictability. Review of Financial Studies 211533 - 1575.

- Fama, E. F., \& French, K. R. (1988) Dividend Yields and Expected Stock Returns. Journal of Financial Economics 22, 3-25.

- Kejriwal, M. \& Perron, P. (2008) A Sequential Procedure to Determine the Number of Breaks in Trend with an Integrated or Stationary Noise Component. Working Paper, Boston University, February 2008, http://people.bu.edu/perron/papers/.

- Lewellen, J., 2004. Predicting returns with financial ratios. Journal of Financial Economics 74, 209-235.

- Mankiw, N.G. \& Shapiro, M.D., (1986) Do we reject too often? Small sample properties of tests of rational expectations models. Economics Letters 20, 139-145.

- Lo, A. W. \& MacKinlay, A. C. (1990a), When are Contrarian Profits Due to Stock Marekt Overreaction? Review of Financial Studies 3, 175-208.

- Lo, A. W. \& MacKinlay, A. C. (1990b) An Econometric Analysis of Nonsynchronous Trading. Journal of Econometrics, 45, 181-211 
- Newey, W. \& West, K.D. (1987) A Simple, Positive Semi-definite, Heteroskedasticity and Autocorrelation Consistent Covariance Matrix, Econometrica 55, 703-708.

- Perron, P. \& Yabu, T. (2009) Estimating Deterministic Trends with an Integrated or Stationary Noise Component. Journal of Econometrics 151, 56-69.

- Stambaugh, R.F. (1986) Bias in regressions with lagged stochastic regressors. Working Paper. University of Chicago, Chicago.

- Stambaugh, R.F. (1999) Predictive regressions. Journal of Financial Economics 54, 375-421.

- Torous, W., Valkanov, R., \& Yan, S. (2004) On predicting stock returns with nearly integrated explanatory variables. Journal of Business 77, 937-966.

- White, H. A. (1980) Heteroskedasticity-Consistent Covariance Matrix Estimator and a Direct Test for Heteroskedasticity, Econometrica 48, 817-838. 


\section{Table 1}

\section{Structural Break Test for Univariate Dividend Yield Regression}

\begin{tabular}{|c|c|c|c|c|}
\hline & \multicolumn{2}{|c|}{$\begin{array}{c}\text { Bai-Perron } \\
\text { (Jan. } 1980 \text { to Dec. 2006) }\end{array}$} & \multicolumn{2}{|c|}{$\begin{array}{l}\text { Kejriwal-Perron-Yabu } \\
\text { (Jan. } 1970 \text { to Dec. 2006) }\end{array}$} \\
\hline & break points & test stat. & break points & test stat. \\
\hline One break & Dec. 1989 & $\begin{array}{l}92.56^{*} \\
(8.58)\end{array}$ & Jan. 1987 & $\begin{array}{l}8.75^{*} \\
(4.13)\end{array}$ \\
\hline Two breaks & $\begin{array}{l}\text { Sep. } 1985 \\
\text { Dec. } 1989\end{array}$ & $\begin{array}{l}96.35^{*} \\
(7.22)\end{array}$ & $\begin{array}{l}\text { Jan. } 1987 \\
\text { Aug. } 1990\end{array}$ & $\begin{array}{l}4.77^{*} \\
(4.53)\end{array}$ \\
\hline Three breaks & $\begin{array}{l}\text { Sep. } 1985 \\
\text { Jul. } 1990 \\
\text { Jun. } 1996\end{array}$ & $\begin{array}{c}3.36 \\
(5.96)\end{array}$ & $\begin{array}{c}\text { Sep. } 1985 \\
\text { Jul. } 1990 \\
\text { Jun. } 1996\end{array}$ & $\begin{array}{c}1.29 \\
(4.83)\end{array}$ \\
\hline
\end{tabular}

Bai \& Perron's $(1998,2003)$ multiple structural break test, and PerronYabu's (2009) and Kejriwal-Perron's (2008) test allowing an I(1) process are applied for log dividend yields. An asterisk $(*)$ denotes that break points are statistically significant at the $5 \%$ level. In parentheses under the test statistics are the $5 \%$ critical values. 
Table 2

Tests of Predictability

\begin{tabular}{lcccccc}
\hline & obs. & $\widehat{\delta}$ & DF-GLS & $95 \%$ CI: $\rho$ & OLS $\widehat{\beta}$ & $90 \%$ CI: $\beta$ \\
\hline \hline (1) Monthly & & & & & & \\
1970:6-2006:6 & 432 & -0.646 & -0.145 & {$[0.996,1.004]$} & 0.003 & {$[-0.012,0.003]$} \\
1990:1-2006:6 & 192 & -0.641 & -0.199 & {$[0.989,1.009]$} & 0.034 & {$[-0.020,0.025]$} \\
& & & & & & \\
(2) Quarterly & & & & & & \\
70:2Q-06:2Q & 146 & -0.716 & -0.475 & {$[0.981,1.012]$} & 0.022 & {$[-0.024,0.026]$} \\
90:1Q-06:2Q & 65 & -0.686 & -0.873 & {$[0.924,1.013]$} & 0.126 & {$[-0.022,0.128]$} \\
\hline
\end{tabular}

Bonferroni test based on DF-GLS test and the Q test. See Campbell \& Yogo (2006) for the details. For OLS $\widehat{\beta}$ and confidence intervals for $\beta$, we report $\widetilde{\beta}=\left(\widehat{\sigma}_{\epsilon} / \widehat{\sigma}_{u}\right) \widehat{\beta}$ where $\widetilde{\beta}$ is the coefficient when innovations are normalized to have unit variance (i.e., $\widehat{\sigma}_{\epsilon}=\widehat{\sigma}_{u}=1$ ). $\widehat{\delta}$ is the correlation between two innovations, hence $\widehat{\delta}=\widehat{\sigma}_{u e} / \widehat{\sigma}_{u} / \widehat{\sigma}_{\epsilon}$. 


\section{Table 3}

Stock Return Predictability with and without Lag Returns

\begin{tabular}{|c|c|c|c|c|c|}
\hline & \multicolumn{2}{|c|}{$(d-p)_{t-1}(\times 100)$} & \multicolumn{2}{|c|}{$r_{t-1}$} & \multirow[t]{2}{*}{ Adjusted $R^{2}$} \\
\hline & White & $\mathrm{N}-\mathrm{W}$ & White & $\mathrm{N}-\mathrm{W}$ & \\
\hline \multicolumn{6}{|c|}{ Full sample } \\
\hline & \multicolumn{2}{|c|}{0.420} & \multicolumn{2}{|c|}{0.346} & \multirow{3}{*}{0.118} \\
\hline [S.E.] & [0.422] & {$[0.432]$} & {$[0.056]$} & [0.049] & \\
\hline [p-value] & {$[0.32]$} & {$[0.33]$} & {$[0.00]$} & {$[0.00]$} & \\
\hline \multicolumn{6}{|c|}{ Subsample } \\
\hline & \multicolumn{2}{|c|}{2.700} & \multicolumn{2}{|c|}{0.312} & \\
\hline [S.E.] & {$[1.227]$} & [1.308] & [0.078] & {$[0.074]$} & 0.108 \\
\hline [p-value] & {$[0.03]$} & {$[0.04]$} & {$[0.00]$} & {$[0.00]$} & \\
\hline
\end{tabular}

Regression results for monthly stock return including dividend yields and lagged return. Full sample is 1970:6-2006:6 and the subsample is 1990:12006:6. Numbers reported in columns titled "White" uses White's (1980) heteroscedasticity consistent estimator in calculating standard errors and "N-W" uses Newey \& West (1987). 
Figure 1. Log Dividend Yield: January 1970 to December 2006

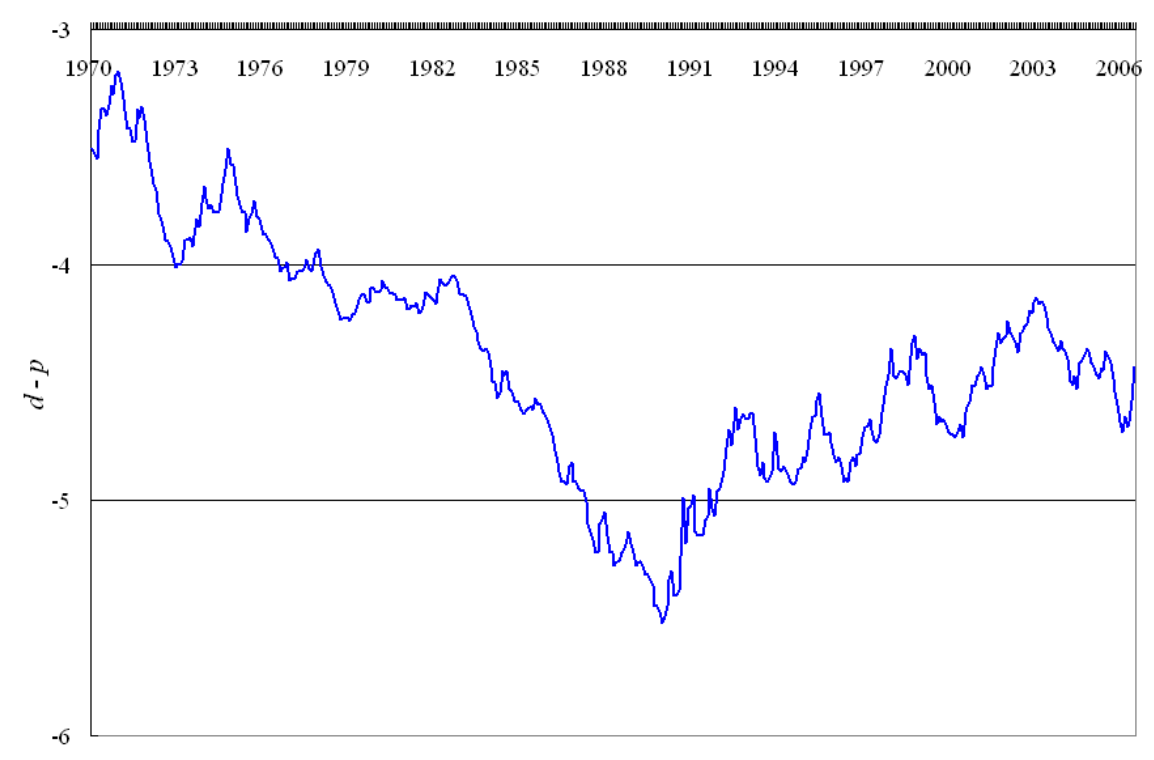




\section{Figure 2. Bonferroni Confidence Intervals for Dividend Yield}

These figures plot the $90 \%$ confidence interval for $\beta$ over the confidence interval for $\rho$, based on $Q$ test. For monthly data, full sample is 1970:62006:6 and the subsample is 1990:1-2006:6. For quarterly data, full sample is $1970: 3 \mathrm{Q}-2006: 2 \mathrm{Q}$ and the subsample is $1990: 1 \mathrm{Q}-2006: 2 \mathrm{Q}$.

(1) Monthly data
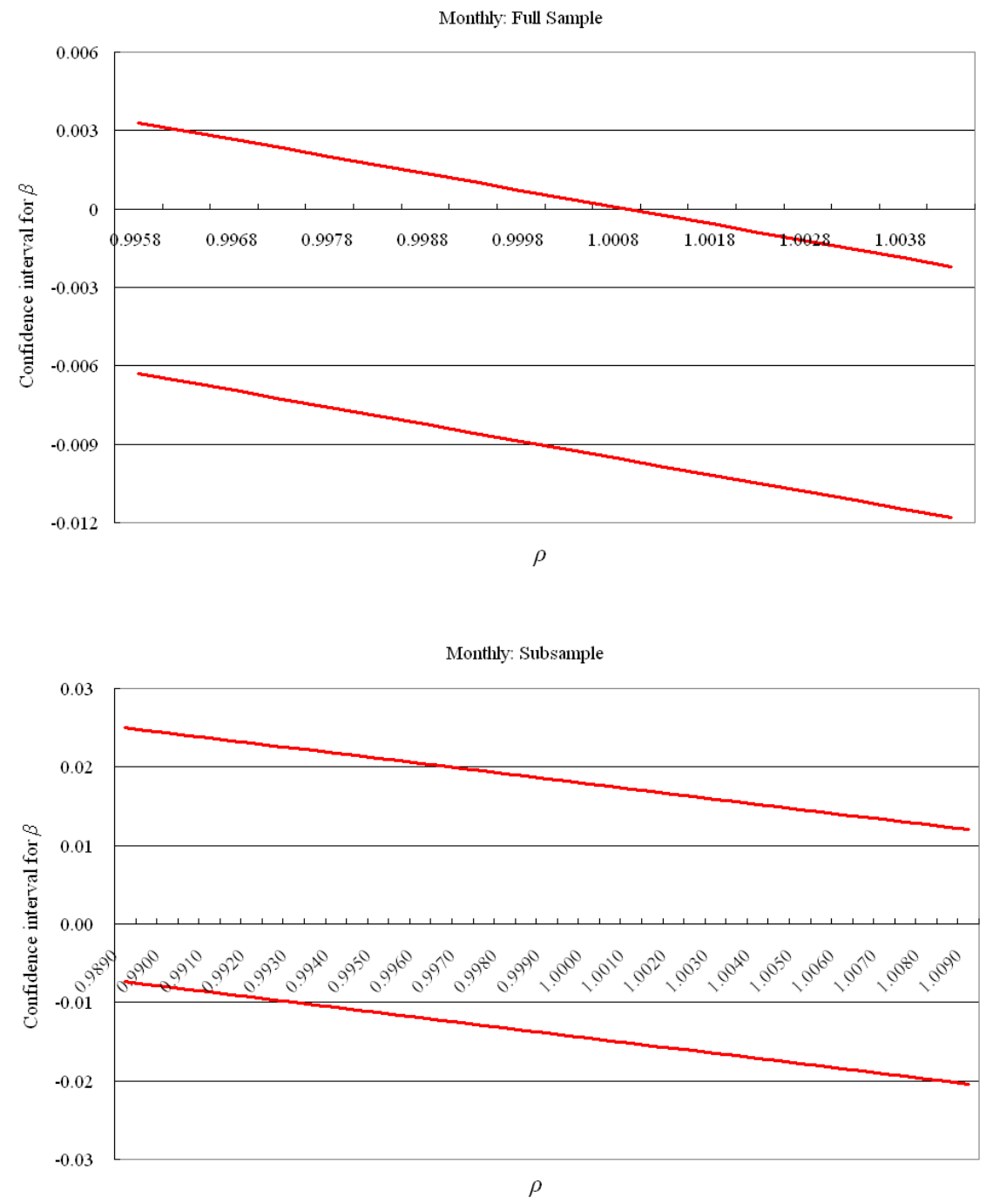
Figure 2 (continued).

(2) Quarterly data
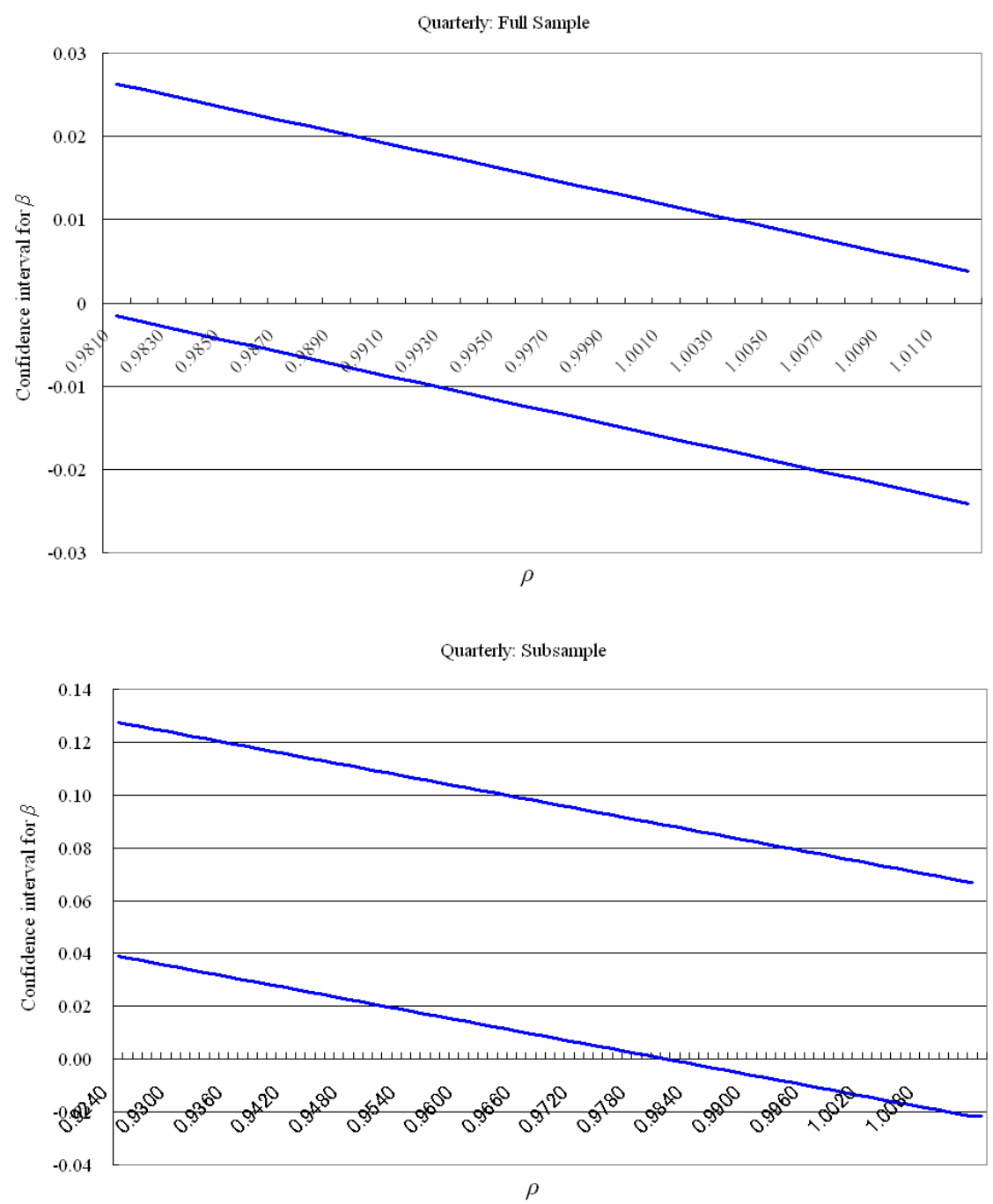